Research Article

\title{
Preparation and Characterization of Hydrophobic-Associated Microspheres for Deep Profile Control in Offshore Oilfields
}

\author{
Qin Yu (D, Xiangguo Lu, Yubao Jin, Cui Zhang, Kuo Liu, and Xinbao Hu \\ Key Laboratory of Enhanced Oil and Gas Recovery of Education Ministry, Northeast Petroleum University, Daqing 163318, China \\ Correspondence should be addressed to Qin Yu; y187459762379@163.com
}

Received 15 November 2017; Revised 29 March 2018; Accepted 17 April 2018; Published 24 June 2018

Academic Editor: Ulrich Maschke

Copyright ( 2018 Qin Yu et al. This is an open access article distributed under the Creative Commons Attribution License, which permits unrestricted use, distribution, and reproduction in any medium, provided the original work is properly cited.

\begin{abstract}
Microspheres have excellent sealing performances such as injectivity, bridging-off, deep migration, and deformation performances, but their plugging effects are limited by the fast swelling rate and poor viscoelasticity. In this study, we synthesized a novel modified microsphere with polymerizable surfactant monomers and cationic monomers. We investigated the influence factors on the swelling performance and rheological properties of the microspheres and explored the ways to improve the plugging performance of hydrophobic-associating microspheres. The association behaviors in aqueous media of poly(acrylamide-comethacry loyloxyethyl trimethyl ammonium chloride-co-n-dodecyl poly(etheroxy acrylate) P(AM-DMC-DEA) are proven to be mediated by the DEA content. Moreover, the hydrophobic association interaction has a strong effect on the performance of microspheres such as swelling properties, the rheological performance, and plugging properties. The swelling properties of microsphere studies exhibited the slow swelling rate. The rheological performance measurements showed significant improvements; yield stress, and creep compliance increased rapidly from 404 to $2060 \mathrm{~Pa}$ and $3.89 \times 10^{-4}$ to $1.41 \times 10^{-2} 1 / \mathrm{Pa}$, respectively, with DEA content in microspheres rising from $0.0 \%$ to $0.22 \%$. The plugging properties of microspheres were enhanced by the slow swelling performance and good viscoelasticity.
\end{abstract}

\section{Introduction}

The reservoirs of the Bohai offshore oilfield in China have the characteristics of low bonding strength, high oil viscosity, and severe heterogeneity. Excess water production can easily cause rock structure destruction and form the macroscopic throats or high-permeability channels in these reservoirs, especially near the wellbore [1-3]. This problem can be solved by deep profile modification to further improve water flooding efficiency. Polymer microspheres overcome the gelation chances reduced of a delayed crosslinking system, due to the shearing, degradation, adsorption, dilution, and gravitational differentiation during underground migration. As one type of "green" water plugging, profile control, and oil displacement, polymer microspheres have the characteristics of plugging a large macrofracture and a small pore passage in the porous medium. These behaviors of selective plugging avoided damage to low-permeability reservoirs. The excellent injection ability of microspheres is due to its low viscosity, discontinuous water, and micro-/nanosize with good matching between pore throats $[4,5]$. Polymer microspheres are a type of microgels and swell after absorbing water, giving rise to bridging-off and a sealing effect on the pore throat. And its elastic deformation caused in the pore throat contributes to in-depth fluid diversion when the injection pressure exceeds the breakthrough pressure $[6,7]$.

Restricted by the condition in the Bohai offshore oilfields, such as unconsolidated reservoir rock and screen pipe completion and compelling, we present some requirements to the microsphere performance, involving the injection performance and slowly swelling properties. The small particle size avoids oversized or completely expanding microspheres from stemming at the well bottom. The slowly swelling properties prevent artificially high injection pressure from damaging to the formation. Recent researches have been carried out on the profile control mechanism of microspheres [8-10]. Slow swelling rate of microspheres avoids blocking in the zone close to the wells and increases core injectivity $[3,11]$. Deformability of microspheres is conducive to shear resistance and deep migration $[12,13]$. Therefore, there is a need 
TABLe 1: Brine components.

\begin{tabular}{lcccccccc}
\hline Ion & $\mathrm{K}^{+}+\mathrm{Na}^{+}$ & $\mathrm{Ca}^{2+}$ & $\mathrm{Mg}^{2+}$ & $\mathrm{Cl}^{-}$ & $\mathrm{SO}_{4}{ }^{2-}$ & $\mathrm{CO}_{3}{ }^{2-}$ & $\mathrm{HCO}_{3}{ }^{-}$ & $\mathrm{Total}(\mathrm{mg} / \mathrm{L})$ \\
\hline Concentration $\mathrm{mg} / \mathrm{L}$ & 2968.8 & 826.7 & 60.8 & 6051.6 & 60.0 & 0.0 & 208.7 & 10176.6 \\
\hline
\end{tabular}

for slow swelling rate and good deformability that can overcome blocking near bore and migrate into the deep reservoirs. To improve the mechanical strength of traditional hydrogels, researchers have made efforts to develop chemically modified materials with novel structures, such as topological gels [14], nanocomposite gel [15-18], double network gel [19], polymer microsphere composite hydrogel [20, 21], hydrophobic association hydrogel $[22,23]$, and tetrapolyethylene glycol hydrogel [24].

Here, we present a new approach to prepare microspheres with slow swelling rate based on hydrophobic association between macromolecules [25, 26]. N-dodecyl poly(etheroxy) acrylate $\left(\mathrm{DEA} ; \mathrm{C}_{12} \mathrm{H}_{25}\left(\mathrm{OCH}_{2} \mathrm{CH}_{2}\right)_{\mathrm{n}} \mathrm{OCOCH}=\mathrm{CH}_{2}\right)$ has also been reported as a polymerizable nonionic surfactant. Compared to ordinary hydrophobic association monomers, DEA with surface activity could improve the emulsion stability and solid content [3]. Moreover, it could form bilayer membranes in the presence of a small amount of an ionic surfactant and onion-like multilayer lamellar in water above the Krafft point $\left(50^{\circ} \mathrm{C}\right)$ [25]. After polymerization, the periodic structure of poly-DEA bilayer membranes or the onion-like structure is very chronically stable at room temperature. It could be suggested that the structure contributes to swelling rate control and viscoelasticity enhancement, due to the hydrophobic association. And the cationic monomers of methacryloyloxyethyl trimethyl ammonium chloride (DMC) could enhance the adsorption capacity of polymers in the formations through static electricity. In this study, a series of hydrophobic association polymer microspheres were prepared from surface-active monomers of DEA, cationic monomers of DMC, and acrylamide (AM) through the water-in-oil (W/O) emulsion method. The swelling properties, rheological properties, and plugging performance were examined by laser particle characterization, rheometry, and core flooding experiment, respectively.

\section{Experimental}

2.1. Materials. The materials used here included acrylamide (AM), dodecyl poly(etheroxy) acrylate (DEA, $\mathrm{C}_{12} \mathrm{H}_{25}\left(\mathrm{OCH}_{2}\right.$ $\left.\mathrm{CH}_{2}\right)_{23} \mathrm{OCOCH}=\mathrm{CH}_{2}$ ), sodium chloride, urea, ethylenediaminetetraacetic acid disodium, sodium acetate (Tianjing Kemiou Chem. Co. Ltd., China), Tween 60, Span-60 (Tianjing Fuchen Chem. Co. Ltd., China), liquid paraffin, sodium sulfite, $\mathrm{N}, \mathrm{N}^{\prime}$-methylene-bis-acrylamide (MBA), ammonium persulfate, (Tianjin Damao Chem. Co. Ltd., China), and methacryloyloxyethyl trimethyl ammonium chloride (DMC, content 65\%, Kelamayi Chem. Co. Ltd., China). These materials were of all analytical grade. Brine with the total salinity of $10176.6 \mathrm{mg} / \mathrm{L}$ was used here, and its main components are listed in Table 1.

2.2. Preparation of PADD Terpolymers. PADD was the terpolymer synthesized from AM, DMC, and DEA in a
TABLE 2: Reaction conditions of terpolymers.

\begin{tabular}{lccccc}
\hline $\begin{array}{l}\text { Identification } \\
\text { code }\end{array}$ & $\begin{array}{c}\text { AM } \\
(\mathrm{g})\end{array}$ & $\begin{array}{c}\text { DMC } \\
(\mathrm{g})\end{array}$ & $\begin{array}{c}\text { DEA } \\
(\mathrm{g})\end{array}$ & $\begin{array}{c}\text { DEA } \\
\text { mol\% }\end{array}$ & $\begin{array}{c}\mathrm{H}_{2} \mathrm{O} \\
(\mathrm{g})\end{array}$ \\
\hline PADD-0.0 & 19.80 & 15.69 & 0 & 0 & 64 \\
PADD-0.16 & 19.36 & 15.36 & 0.64 & 0.16 & 64 \\
PADD-0.22 & 19.21 & 15.24 & 0.88 & 0.22 & 64 \\
PADD-0.28 & 19.05 & 15.14 & 1.11 & 0.28 & 64 \\
PADD-0.34 & 18.89 & 15.02 & 1.34 & 0.34 & 64 \\
\hline
\end{tabular}

The concentration of ethylenediaminetetraacetic acid disodium salt and urea were at 56 and $3 \times 10^{4} \mathrm{mg} \cdot \mathrm{L}^{-1}$, respectively.

polymerization unit with a flask consisting of a thermostatic bath and a turning base provided with a controlled speed. At first, AM, DMC, and DEA were mixed into a $250 \mathrm{~mL}$ flask added with distilled water according to the amounts showed in Table 2 . Then, the polymerization system was placed into a water bath and maintained at $45^{\circ} \mathrm{C}$ for $5 \mathrm{~h}$, after purging with nitrogen. Ammonium persulfate and sodium sulfite were used as redox initiators at concentrations of 0.42 and 0.84 $w / w \%$ (monomer mass), respectively. All samples were purified. The polymers were recovered by methanol precipitation, filtration, and oven-drying at $50^{\circ} \mathrm{C}$.

2.3. Preparation of MADD Microspheres. MADD was the microsphere synthesized from AM, DMC, and DEA by inverse emulsion copolymerization. Typically, $19.25 \mathrm{~g}$ of Span 60 and $2.15 \mathrm{~g}$ of Tween 60 were dispersed in $120 \mathrm{~g}$ of liquid paraffin in a three-necked flask. As showed in Table 3, AM, DMC, DEA, $0.18 \mathrm{~g}$ of MBA, and $0.22 \mathrm{~g}$ of ammonium persulfate were dissolved in $55 \mathrm{~g}$ of distilled water; the system was dispersed dropwise in the above oil phase under vigorous stirring. After a homogenous solution was formed, the system was added with $0.43 \mathrm{~g}$ of sodium sulfite solution (dissolved in $5 \mathrm{~g}$ of distilled water) to initiate the polymerization under nitrogen protection and stirring for $5 \mathrm{~h}$ at $45^{\circ} \mathrm{C}$. The microsphere emulsions as-obtained were diluted twofold with hexane and poured into excessive methanol. The precipitated polymer microspheres were separated by filtration and then repeatedly washed with hexane to remove liquid paraffin and also with acetone to wash off the residual surfactant. After the last washing, the polymer microspheres were vacuumdried at $50^{\circ} \mathrm{C}$ for $48 \mathrm{~h}$ and kept in a desiccator until further use. The polymerization reaction is illustrated in Figure 1.

\subsection{Characterizations}

(1) The precursors and microspheres were characterized by ${ }^{13} \mathrm{C}$ nuclear magnetic resonance (NMR) in $\mathrm{D}_{2} \mathrm{O}$ and solid-state ${ }^{13} \mathrm{C}$ NMR, respectively, using a Brucker Avance III spectrometer (500 Mhz) and a Brucker Avance 400 spectrometer ( $400 \mathrm{Mhz}$ ) at constant temperature $\left(25^{\circ} \mathrm{C}\right)$. 
TABLE 3: Reaction conditions of terpolymer microspheres.

\begin{tabular}{|c|c|c|c|c|c|c|c|c|}
\hline Identification code & $\mathrm{AM}(\mathrm{g})$ & $\mathrm{DMC}(\mathrm{g})$ & DEA (g) & DEA mol\% & Sp60 (g) & Tween $60(\mathrm{~g})$ & Liquid paraffin $(\mathrm{g})$ & $\mathrm{H}_{2} \mathrm{O}(\mathrm{g})$ \\
\hline MADD-0.0 & 16.98 & 13.44 & 0 & 0 & 19.25 & 2.145 & 120 & 55 \\
\hline MADD-0.16 & 16.60 & 13.16 & 0.55 & 0.16 & 19.25 & 2.145 & 120 & 55 \\
\hline MADD-0.22 & 16.46 & 13.07 & 0.75 & 0.22 & 19.25 & 2.145 & 120 & 55 \\
\hline MADD-0.28 & 16.33 & 12.96 & 0.95 & 0.28 & 19.25 & 2.145 & 120 & 55 \\
\hline MADD-0.34 & 16.20 & 12.87 & 1.15 & 0.34 & 19.25 & 2.145 & 120 & 55 \\
\hline
\end{tabular}

Ammonium persulfate and sodium sulfite were used as redox initiators at the concentrations of 0.55 and $1.1 w / w \%$ (monomer mass), respectively. N,Nmethylene-bis-acrylamide $(0.47 w / w \%$ monomer mass $)$ was used as a crosslinking agent.<smiles>C=CC(=O)C=CC(C)(C)C(=O)OCC[N+](C)(C)C(Cl)=CC=CC(=O)OCCCCCC(N)=O</smiles>

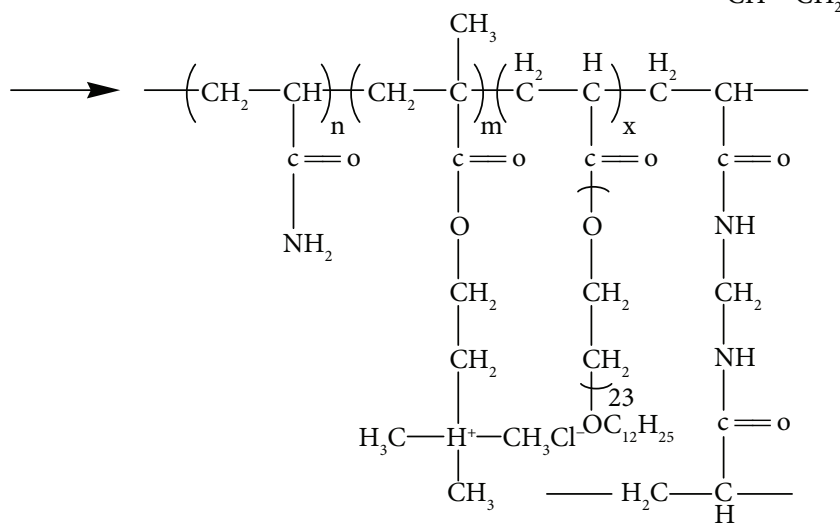

FIGURE 1: Reaction schemes and molecular structures of monomers and hydrophobical copolymer microspheres.

(2) The surface tensions of the microsphere solution and DEA solution were determined by an automatic surface tension meter (Model QBZY, Shanghai Fangrui Instrument Co. Ltd.) at constant temperature $\left(25^{\circ} \mathrm{C}\right)$. To prepare the microsphere solution, a certain amount of emulsion and a small amount of Tween 60 were dispersed into $1000 \mathrm{~mL}$ of simulated water and mixed well. The DEA solution was dissolved in simulated water.

(3) The particle size and distribution of the microspheres were investigated with a Mastersizer 2000 analyzer (MaErWen Company, UK) based on laser diffraction at constant temperature $\left(25^{\circ} \mathrm{C}\right)$ and $\mathrm{He}-\mathrm{Ne}$ lasers at $630.0 \mathrm{~nm}$. To obtain the original particle size of the microspheres, ethanol was used as the circulating liquid, and $0.5 \mathrm{~g}$ of emulsion was dispersed into $1000 \mathrm{~mL}$ of ethanol, followed by the addition of a few drops of Tween 60 as the dispersing agent. To measure the average particle diameters after water absorption, $0.5 \mathrm{~g}$ of emulsion and a small amount of Tween 60 were dispersed into $1000 \mathrm{~mL}$ of simulated water and swollen at $45^{\circ} \mathrm{C}$; the swollen microspheres were taken out at regular interval and measured. Shading degree was set between $10 \%$ and $20 \%$.

(4) Rheological properties were measured at $25^{\circ} \mathrm{C}$ with an Anton Paar Physica MCR 301 rheometer equipped with a cone-plate geometer (diameter 35 or $60 \mathrm{~mm}$, angle $1^{\circ}$ ). The purified polymers were dissolved in the brine to the concentration of $0.20 \mathrm{wt} \%$ and then gently stirred for $24 \mathrm{~h}$. All the polymer solutions were perfectly clear and transparent. The apparent viscosity and 1st normal stress difference were measured at various shear rates $\left(Y \approx 10^{-2} \sim 10^{3} \mathrm{~s}^{-1}\right)$. Rheological behavior of microspheres was evaluated by the rheometer using a flatbed C60/1 system. The experimental conditions were as follows: (1) stress sweep, a shear stress of $0 \sim 600 \mathrm{~Pa}$ and frequency of $1 \mathrm{~Hz}$, and (2) creep and recovery, the shear stress suddenly disappeared after constant shear stress $2.5 \mathrm{~Pa}$ for $240 \mathrm{~s}$ at a frequency of $1 \mathrm{~Hz}$. Creep compliance and recoverable deformation were detected. Creep was measured at $45^{\circ} \mathrm{C}$. Unless otherwise mentioned, the samples were heated at a certain temperature for $10 \mathrm{~min}$, and their thickness was about $2.3 \mathrm{~mm}$. The reaction and tests were the same and performed at reservoir temperature $45^{\circ} \mathrm{C}$.

(5) The morphology of microspheres was investigated with an ultradepth three-dimensional electron microscope (Kenshi Company, Japan) based on transmission light at constant temperature $\left(25^{\circ} \mathrm{C}\right)$ in VHX-1000C model and at magnification between 20x and 5000x. To obtain the morphology of the microspheres, $0.5 \mathrm{~g}$ of emulsion was dispersed into $1000 \mathrm{~mL}$ of water, followed by the addition of a few drops of Tween 60 as the dispersing agent.

(6) The gel plugging efficiency in porous media was tested using a core flooding instrument. The cores were quartz sand cemented by epoxy resin homogeneously. Their permeability $(\mathrm{Kg})$ was $240 \times 10^{-3} \mu \mathrm{m}^{2}$ and $1500 \times 10^{-3} \mu \mathrm{m}^{2}$. The cores were weak oil-wet with the porosity of the core measured as 0.256 . The size of these cores was at $4.5 \times 4.5 \times 30 \mathrm{~cm}^{3}$ 


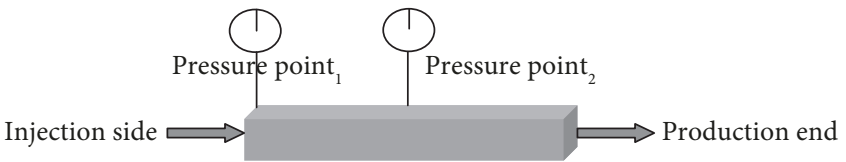

Figure 2: Diagram of the core and the value installation position.

(height $\times$ width $\times$ length). The core with the $\mathrm{Kg}$ of $240 \times 10^{-3} \mu \mathrm{m}^{2}$ was added with another pressure measurement point at $15 \mathrm{~cm}$ from the inlet. As shown in Figure 2, microspheres were injected into the core through the "injection side", and then the valve was closed. After placement for $24 \mathrm{~h}$ at $45^{\circ} \mathrm{C}$, the valves were opened and flooded with water while the pressures were observed and recorded. The specific experimental equipment and process are shown in [27]. The concentration of microspheres was $3000 \mathrm{mg} / \mathrm{L}$, and the injection rate was $0.3 \mathrm{~mL} / \mathrm{min}$.

The resistance factor ( $\mathrm{RF}$ ) was determined by the ratio of the pressure drop for microsphere injection to that of the initial water injection as follows:

$$
\mathrm{RF}=\frac{\left(k_{w} / \mu_{w}\right)_{\text {basewater }}}{\left(k_{w} / \mu_{w}\right)_{\text {microsphere }}}=\frac{\Delta P_{\text {microsphere }}}{\Delta P_{\text {basewater }}} .
$$

The residual resistance factor (RRF) was determined by the ratio of the pressure drop for post water injection to that of the initial water injection as follows:

$$
\mathrm{RRF}=\frac{\left(k_{w} / \mu_{w}\right)_{\text {basewater }}}{\left(k_{w} / \mu_{w}\right)_{\text {postwater }}}=\frac{\Delta P_{\text {postwater }}}{\Delta P_{\text {basewater }}}
$$

The pressure gradient was defined as the ratio of pressure drop to the injection distance as follows:

$$
\begin{gathered}
\left(\frac{\Delta P}{\Delta L}\right)_{\text {basewater }}=\frac{(\Delta P)_{\text {basewater }}}{(\Delta L)_{\text {basewater }}} \\
\left(\frac{\Delta P}{\Delta L}\right)_{\text {microsphere }}=\frac{(\Delta P)_{\text {microsphere }}}{(\Delta L)_{\text {microsphere }}} \\
\left(\frac{\Delta P}{\Delta L}\right)_{\text {postwater }}=\frac{(\Delta P)_{\text {postwater }}}{(\Delta L)_{\text {postwater }}}
\end{gathered}
$$

(7) Fluorescence spectroscopy was used to observe the change in the amount of the hydrophobic domains of the polymers in the aqueous dispersions. As a fluorescence probe, pyrene was solubilized in ethanol to prepare the pyrene solution with concentration of $1 \times 10^{-3} \mathrm{~mol} / \mathrm{L}$. And $250 \mu \mathrm{L}$ pyrene solution was added to $50 \mathrm{~mL}$ volumetric flask and purged by nitrogen to evaporate off the ethanol. Then, the aqueous polymer dispersion was added to the volumetric flask, achieving a final pyrene concentration of
TABLE 4: Intrinsic viscosity of the terpolymers.

\begin{tabular}{lccccc}
\hline Identification & PADD- & PADD- & PADD- & PADD- & PADD- \\
code & 0.0 & 0.16 & 0.22 & 0.28 & 0.34 \\
\hline$[\eta] \mathrm{mL} / \mathrm{g}$ & 132 & 147 & 343 & 327 & 315 \\
\hline
\end{tabular}

$[\eta]$ is the intrinsic viscosity of PADD.

$5 \times 10^{-6} \mathrm{M}$. The solutions were sonicated and left overnight at room temperature. The fluorescence spectra of pyrene were measured using a fluorescence spectrophotometer (Hitachi F-7000). $\lambda_{\text {ex }}$ was set to $339 \mathrm{~nm}$ for the observation of pyrene emission spectra, and $\lambda_{\text {em }}$ was set at $350-550 \mathrm{~nm}$. The slit widths for emission and excitation were set at $2.5 \mathrm{~nm}$.

\section{Results and Discussion}

3.1. Properties of PADD. We prepared the terpolymers with the hydrophobic comonomers using the aqueous solution copolymerization method and investigated how the content of DEA affected the hydrophobic association interaction between molecular chains. The behaviors of linear macromolecules are more likely to be characterized and analyzed than those of the three-dimensional networks. The conclusion of PADD could be used to design the formula of microspheres and explain the interaction of the molecular chain in the three-dimensional networks of the microspheres.

3.2. Intrinsic Viscosity of $P A D D$. Intrinsic viscosity was determined in $1 \mathrm{M} \mathrm{NaCl}$ aqueous dilute solution at $30^{\circ} \mathrm{C}$ using a capillary viscometer (Ubbelohde type), and the intrinsic viscosity was determined as showed in Table 4. Clearly, the intrinsic viscosities of copolymer increased first and then decreased with the rise of DEA content. PADD- 0.22 with the addition of $0.22 \%$ DEA had the largest molecular weight. At lower hydrophobe level, the hydrophobic association interaction between dodecyl in DEA formed a physically cross-linked network and increased its hydrodynamic volume, and the long chain of polyethylene glycol units in DEA stretched in water enlarged its hydrodynamic radius with the increase of DEA content. These changes resulted in the larger molecular weight. However, the higher hydrophobe content reduces the lower intrinsic viscosity. It was estimated that the longer hydrophobic block promoted intramolecular hydrophobic interaction between terpolymers [28, 29], contributing to decrease its hydrodynamic radius and intrinsic viscosity. Moreover, the higher hydrophobe content weakened the free-radical activity during polymerization because the steric hindrance effect of long-chain DEA was enhanced under the condition of higher DEA content [30, 31].

3.3. Rheological Properties of PADD. Figure 3 illustrated how the viscosity varied with the shear rate of PADD polymers. As expected, the apparent viscosity of PADD-0 and PADD0.22 decreased with the increase of shear rate and rose with the concentration of polymer solution; the apparent viscosity of terpolymer rose first and then decreased as a result of the increase in hydrophobic monomer content in the feed. The 

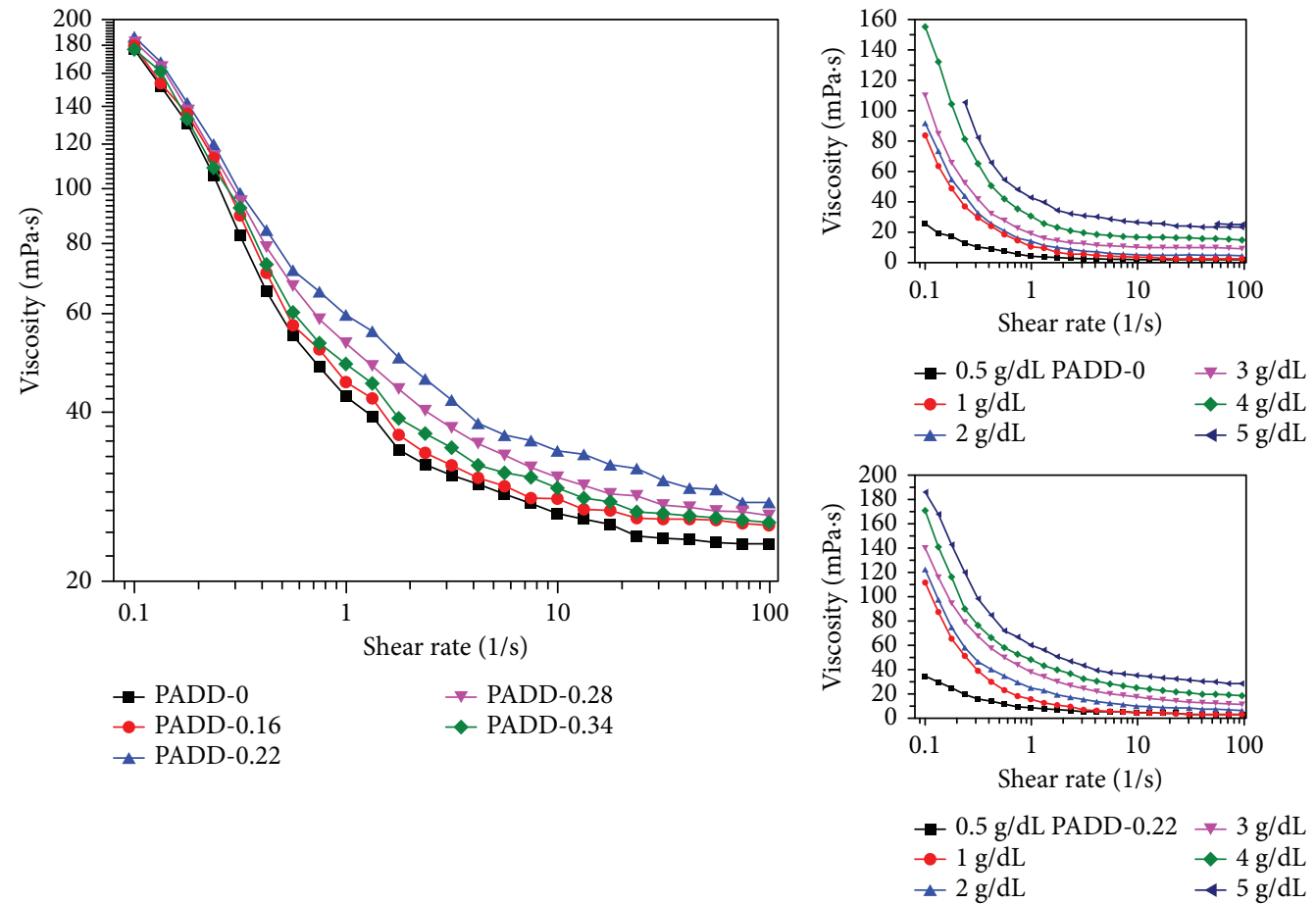

FIGURE 3: Variation of the apparent viscosity of polymer solutions in brine $\left(25.0 \pm 0.1^{\circ} \mathrm{C} ; 5 \mathrm{~g} / \mathrm{dL}\right.$ polymer $)$.

apparent viscosity of polymers increased with the increase of shear rate when DEA content was up to $0.16 \%$. This enhancement of initial viscosity could somewhat be related to intermolecular associations, whereas the other role may result from the variation of molecular weight. This was because the terpolymers with an appropriate DEA content in the main chains formed a stronger intermolecular association and higher physical crosslinking density, which resulted in the flow resistance increase of polymer solution. However, the hydrophobic-associated polymers easily transformed from intramolecular association into intermolecular association (critical association concentration) [27-33], owing to the larger DEA content. Moreover, the decrease of molecular weight in PADD-0.28 reduced the entanglement and association of the polymer, due to the significant steric effects of excessive DEA. The behaviors decreased the interactive force between macromolecules and the apparent viscosity of polymer.

As shown in Figure 4, the loss modulus of polymer rose with the increase of angular frequency. The behaviors were similar to the noticeable shear thickening, due to the hydrophobic disassociation interaction and unwrapping interaction between chains with the shear rate. PADD-0.22 had a larger loss modulus than PADD-0 and showed a sharp increase in the loss modulus, with increasing of polymer concentration. The present results indicated that hydrophobic microblock increased the association interaction as the mole concentration of DEA increased, because the loss modulus of polymer rose with the increasing of hydrophobic association density and physical entanglement links between chains. However, the loss modulus of polymer rose first and then decreased with the DEA content in terpolymers. This phenomenon was attributed to the transformation of
PADD from intramolecular association into intermolecular association, owing to the larger DEA content. As a result, intermolecular interaction forces were weakened, leading to a decrease in viscidity.

3.4. Fluorescence Studies of the Aqueous Polymer Dispersions. To estimate the change in the hydrophobic domain in the polymer aqueous solutions, we performed fluorescence studies using pyrene as a fluorescence probe. The changes in the environment of pyrene are usually determined by monitoring the intensity ratio of the first and third vibrational bands, $\mathrm{I}_{1} / \mathrm{I}_{3}$, in the emission spectra of the peak from around $373 \mathrm{~nm}$ to $384 \mathrm{~nm}$ [34]. As showed in Figure 5, the intensity ratio of pyrene emission spectra decreased significantly with the increasing polymer concentration. The $I_{373} / I_{384}$ value for PADD-0 was higher than the value for PADD-0.22 (1.37$0.97)$. These results were thought to indicate that the amount of hydrophobic domains increased as the DEA content in the copolymer was increased.

3.5. Properties of MADD Microspheres. We attempted to prepare hydrophobic microspheres $\mathrm{P}(\mathrm{AM}-\mathrm{DMC}-\mathrm{DEA})$ by an inverse emulsion polymerization on the basis of the same ion monomer content as PADD and investigated how the nonionic large monomer DEA with surface activity affected the swelling properties, rheological properties, and plugging performance.

3.6. The Morphology of Microspheres. The morphology photos of MADD-0.0 and MADD-0.22 in distilled water are shown in Figure 6. Most of the microspheres were symmetrically spherical and evenly dispersed in water. The initial particle size of MADD-0.0 was less than that of MADD-0.22 

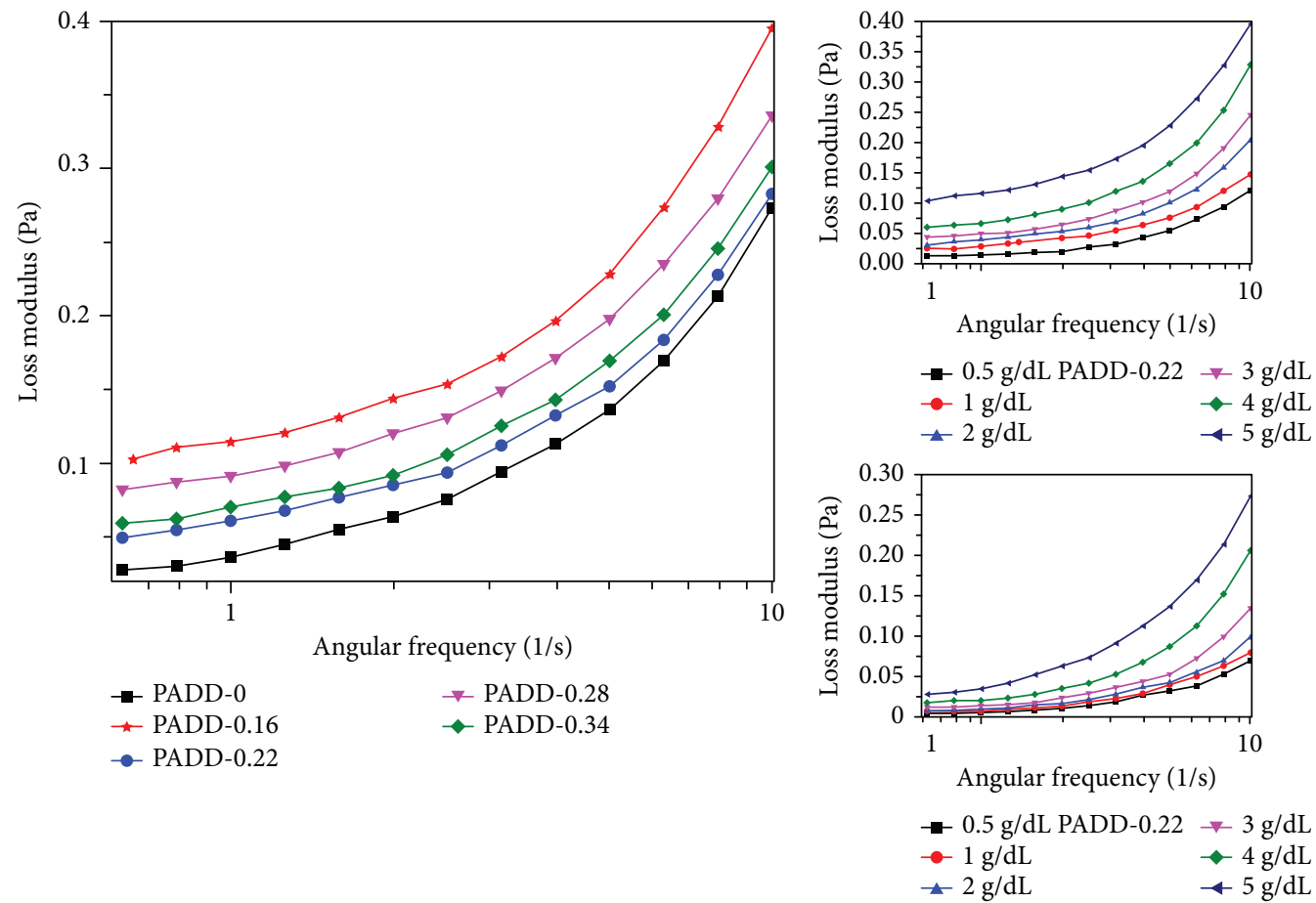

Figure 4: Variation of loss modulus of polymer solutions in brine $\left(25.0 \pm 0.1^{\circ} \mathrm{C} ; 5 \mathrm{~g} / \mathrm{dL}\right.$ polymer $)$.

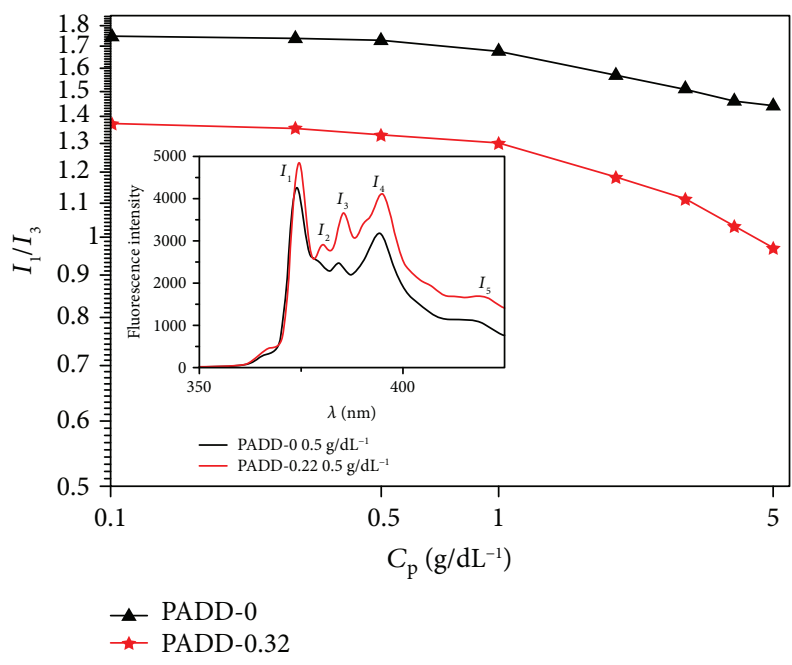

FIGURE 5: Fluorescence spectrum of PADD (probe, pyrene).

under the same magnification. The morphology of MADD0.22 was composed of a central circular core and the outer clear ring. The three-dimensional network structure prepared by ternary copolymerization formed the middle core, and the long chains of DEA in the outer macromolecule chain constituted the circle around the core.

3.7. Structure of Microspheres. Figure 7 shows the ${ }^{13} \mathrm{C}$ NMR spectra of DEA, PAM, MADD-0.0, and MADD-0.22. In Figure $7(\mathrm{a})$, the peak at $171.95 \mathrm{ppm}$ is attributed to COO. The signals at 136.29 and $126.64 \mathrm{ppm}$ can be attributed to the chemical shifts of $\mathrm{C} 1$ and $\mathrm{C} 2$, respectively. The sharp peak at $69.62 \mathrm{ppm}$ corresponds to the signals of $\mathrm{C} 4, \mathrm{C} 5$, and C6. The multiple peaks around 29.97 and $17.41 \mathrm{ppm}$ correspond to the overlapping signals of $\mathrm{C} 7$ and $\mathrm{C} 8$. For PAM, the sharp peak at $180.70 \mathrm{ppm}$ is attributed to $\mathrm{CONH}_{2}$. The sharp peak at $42.43 \mathrm{ppm}$ is the signals of $\mathrm{C} 1$ and C2. In Figure $7(\mathrm{c})$, the typical signal of $-\left(\mathrm{CH}_{3}\right)_{3} \mathrm{~N}^{+}$groups appears at $55.61 \mathrm{ppm}$, the two peaks at 69.09 and $66.22 \mathrm{ppm}$ correspond to the signals of $\mathrm{C} 8$ and $\mathrm{C} 9$, and the sharp peak at $180.29 \mathrm{ppm}$ is attributed to $\mathrm{CONH}_{2}$, which indicates the presence of DMC on MADD-0.0. In Figure 7(d), the typical signal of $\mathrm{CH}_{2}=\mathrm{CH}$ in the spectra of MADD- 0.22 disappears. These characteristic peaks of DMC and DEA, such as $55.50 \mathrm{ppm}$ for $-\left(\mathrm{CH}_{3}\right)_{3} \mathrm{~N}^{+}, 66.08$ and $60.48 \mathrm{ppm}$ for $-\mathrm{OCH}_{2}-$, and $20.03 \mathrm{ppm}$ for $-\mathrm{C}_{11} \mathrm{H}_{23}$ [35], could be observed in the solid-state ${ }^{13} \mathrm{C}$ NMR spectrum of MADD-0.22. It is indicated that microspheres were constructed by combining $\mathrm{AM}, \mathrm{DMC}$, and DEA by cross-linking with $\mathrm{N}, \mathrm{N}^{\prime}$-methylene-bis acrylamide.

3.8. Surface Activity of Microspheres. The surface tensions of the microsphere solution and DEA solution were determined by the suspension method [36] (Figure 8). The surface tension of DEA decreased firstly from 54.7 to $45.2 \mathrm{mN} / \mathrm{m}$ and then increased to $50.9 \mathrm{mN} / \mathrm{m}$, suggesting DEA had a lower reduction of surface tension. Figure 8 shows that MADD0.22 has nearly identical surface tension as MADD-0.0, the surface tension of MADD reduced gradually with the microsphere concentration, and the magnitude of decline was small. The reason was that the hydrophobic block of DEA was in a constant state of contraction due to the strong hydrophobic association between the microsphere chains and slightly or hardly migrated to the gas-liquid interface. Thus, MADD-0.22 had low surface activity. 

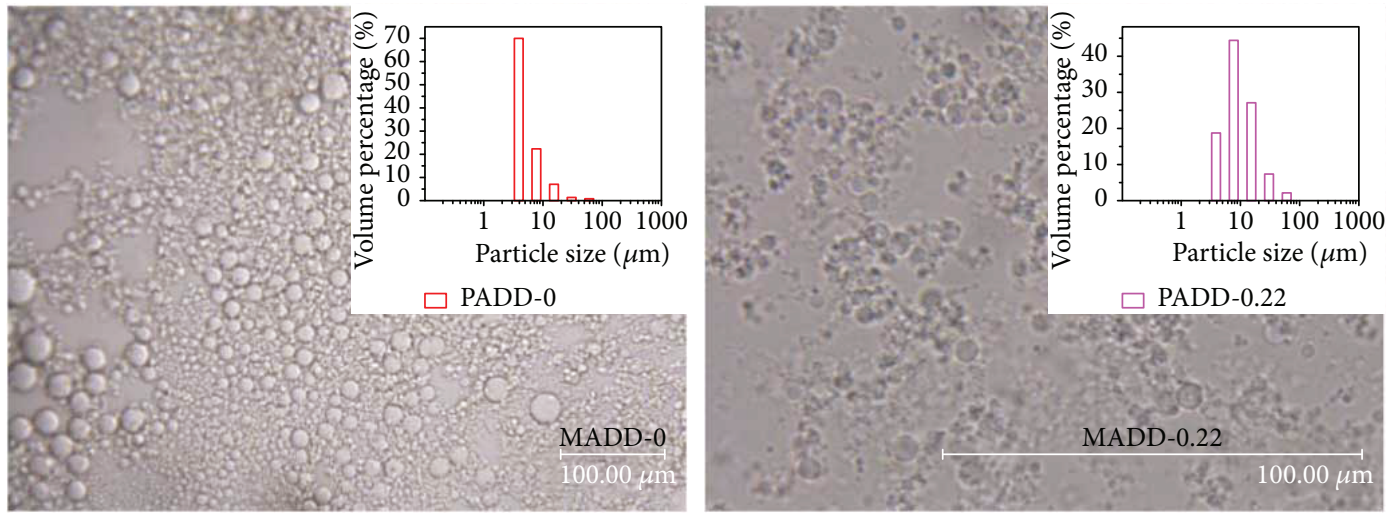

Figure 6: Three-dimensional microscope images of MAAE-0.0 and MAAE-0.22.

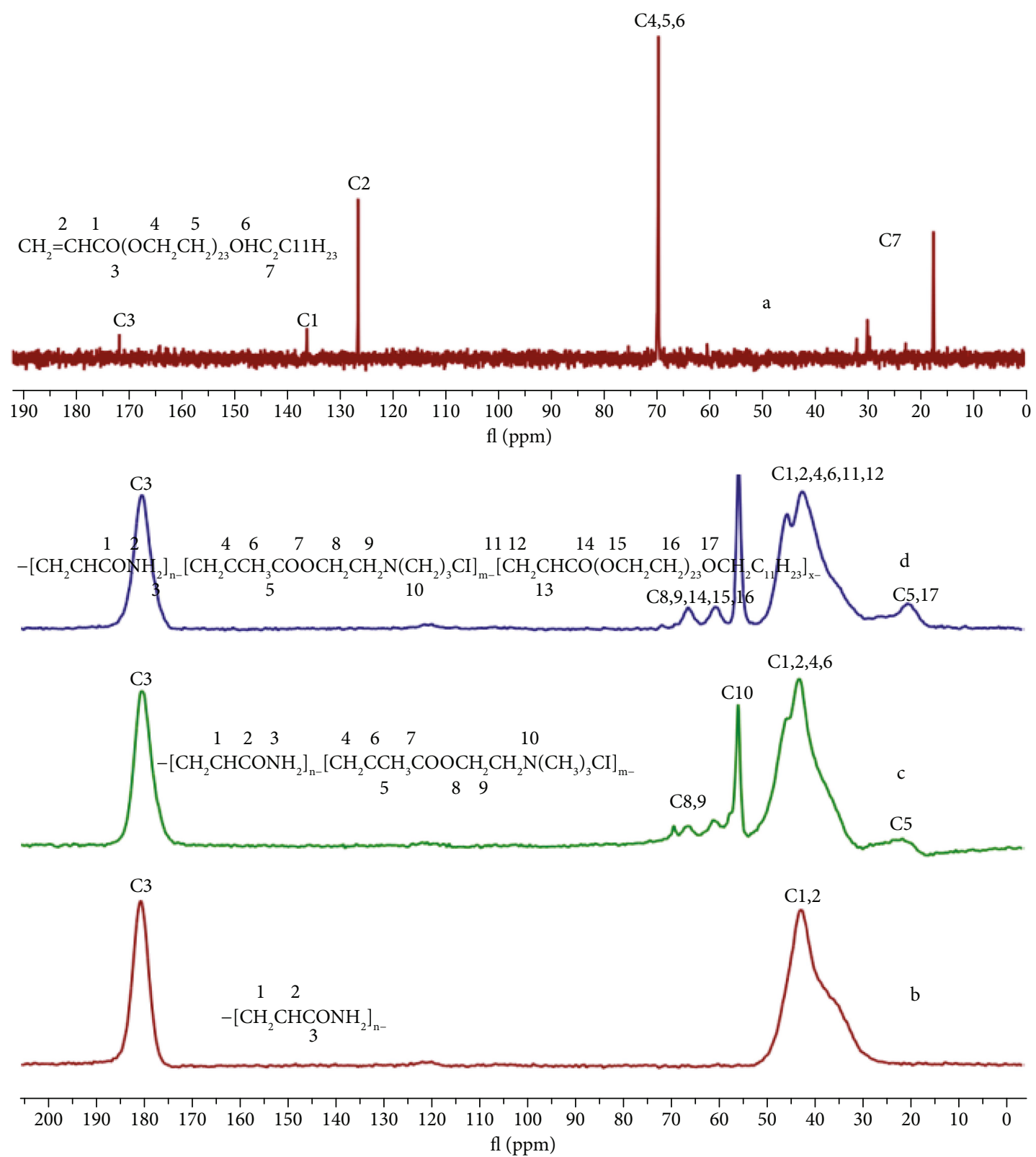

Figure 7: ${ }^{13} \mathrm{C}$ NMR spectra of DEA in $\mathrm{D}_{2} \mathrm{O}$ and solid-state ${ }^{13} \mathrm{C}$ NMR of PAM, MADD-0.0, and MADD-0.22 at $25^{\circ} \mathrm{C}$. 


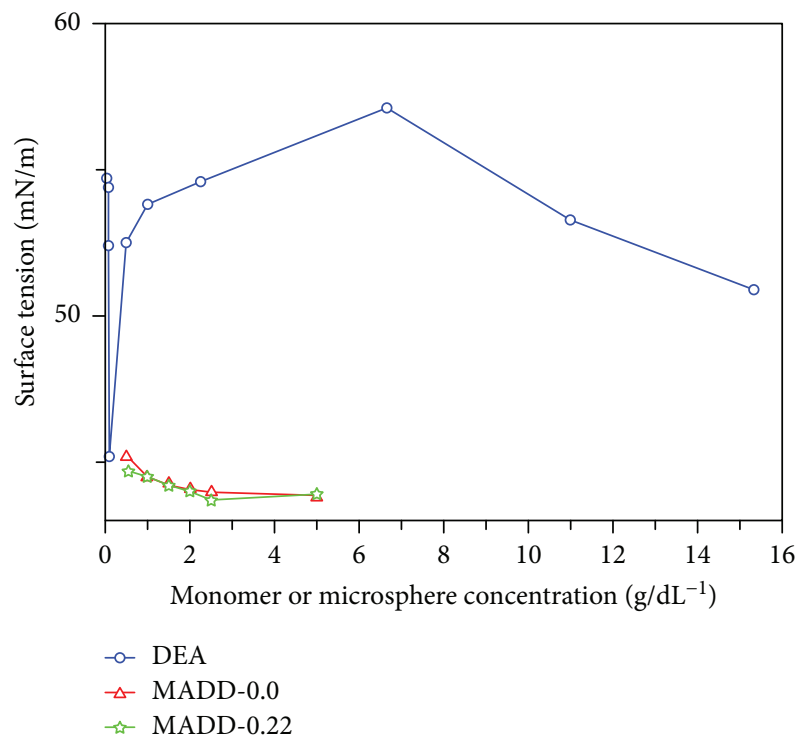

Figure 8: Relationship between surface tension and concentration for MAAE in $10176.6 \mathrm{mg} / \mathrm{L}$ brine at $25.0 \pm 0.1^{\circ} \mathrm{C}$.

3.9. Microsphere Swelling Rate. The swelling rate as a time function for the microspheres in brine is shown in Figure 9. Clearly, the initial particle size increases from 6.36 to $13.43 \mu \mathrm{m}$ with the rise of DEA concentration. The lower DEA concentration in the microspheres accelerates the swelling and shortens the time to reach swelling equilibrium. MADD-0.0 reached $81.7 \%$ equilibrium swelling after one hour of swelling. This behavior was attributed to the long chains of polyethylene glycol units in DEA that increased the hydrodynamic radius of microspheres. The higher DEA concentration in microspheres enlarged the initial particle size. Moreover, surface-active monomer DEA in water formed onion-like double layer vesicles, which persisted after the polymerization [25,37]. The vesicle structure, hydrophobic association of tail chain alkyl, and the intermolecular hydrogen bonding between ether bond and amide group together caused network contraction and decelerated water diffusion [38]. Although the hydrogen bonding was broken down gradually during the gel swelling, the association action as physical crossing points shortened the chain length between network junctions and restricted the gel swelling [39-41]. The stronger association action decelerated the gel swelling.

3.10. Rheological Properties of Microspheres. The gels prepared according to different microsphere formulations were examined by measuring the stress sweep behavior. For linear strain, we evaluated the linear region $G^{\prime}$, the average unit number of network of cross-linked points $(N)$, and the chain length between cross-linking points $L_{\mathrm{c}}$ as follows [42]:

$$
\begin{aligned}
& G^{\prime}=\frac{R T}{N_{\mathrm{AV}} a^{3} N} \phi_{0}{ }^{2 / 3} \phi^{1 / 3}, \\
& L_{\mathrm{C}}=\phi^{-1 / 3}\left(C_{\infty} N\right)^{1 / 2} a,
\end{aligned}
$$

where $G^{\prime}$ is the storage modulus of strong gels at low frequency, $N_{\mathrm{AV}}$ is Avogadro constant, $R$ is the universal gas constant, $T$ is the absolute temperature, and $\phi_{0}$ and $\phi$ are the volume fractions of gel relaxation and swelling, respectively; $N_{\mathrm{AV}} \alpha^{3}$ is the molar volume of the solvent. The dry gels were assumed to be at the relaxed state; $\phi_{0}$ was 1 for all samples. $C_{\infty}$ is a characteristic constant of the gel.

As showed in Figure 10, linear storage modulus, linear loss modulus, and yield stress increase rapidly from 300 to $16500 \mathrm{~Pa}, 161$ to $2850 \mathrm{~Pa}$, and 404 to $2060 \mathrm{~Pa}$, respectively, with DEA content in microspheres rising from $0.0 \%$ to $0.22 \%$ and then decreased with further addition of DEA. These behaviors are attributed to the effect of intermolecular forces on network structures. On one hand, an appropriate addition of DEA could enhance the hydrophobic association action and physical crosslinking and reduce the chain length between network junctions $L_{c}$ [42]. On the other hand, the hydrogen bond formed between ether bond and amide group in chains and water strengthens the ability of enveloping water, thus improving the system viscosity [43-45]. However, the viscoelasticity decreases rapidly with further addition of DEA beyond $0.22 \%$. We thought this behavior in reducing viscosity and elasticity of MADD is mainly attributed to the microheterogeneity of the hydrophobic association networks. That is, due to the decrease in polymerization activity affected by excessive DEA in MADD, there are some suspended chains, ring chains, and structure collapse that help to reduce the network homogeneity and viscoelasticity.

The gels prepared according to different microsphere formulations were tested by measuring the creep recovery behavior. For creep recovery, steady-state compliance $J(t)$, time-dependent strain $(\gamma)$, and constant stress $(\tau)$ have the following relationship [46]: $\gamma(t)=J(t) \cdot \tau$. $J(t)$ is characterized as flexibility of the viscoelastic material. It is suggested that under a given stress, the more easily deformed viscoelasticity would improve the compliance recoverable deformation and elasticity properties.

Figure 11 illustrates the curves of creep recovery changing with DEA contents for MADD gels. MADD gels exhibit instantaneous viscoelastic response, while $J(t)$ rises first (from $3.89 \times 10^{-4}$ to $1.41 \times 10^{-2} 1 / \mathrm{Pa}$ ) and then decreases (from $1.41 \times 10^{-2}$ to $1.44 \times 10^{-3} 1 / \mathrm{Pa}$ ) with the increasing DEA content, and the deformation reverts to the previous motives after the removal of extrinsic incentives (Figure 8). The orientation of polymer chains in hydrogel networks has significant consequences for the creep recovery. It is clear that the conformation of polymer chains would be promoted by the increase of DEA content. MADD-0.0 has lower conformation due to the stress concentration in the shorter chains at any instant. With DEA content increasing from $0.0 \%$ to $0.22 \%$, the orientation on stretching of polymer chains between cross-linked networks is simplified, and the number of polymer chains that bore stress force also increases. However, too strong hydrophobic association complicates the orientation of polymer chains when DEA content is above $0.22 \%$, thus decreasing the steady-state compliance.

3.11. Plugging Properties of Microspheres. The plugging properties of the microspheres in porous media measured by flow 

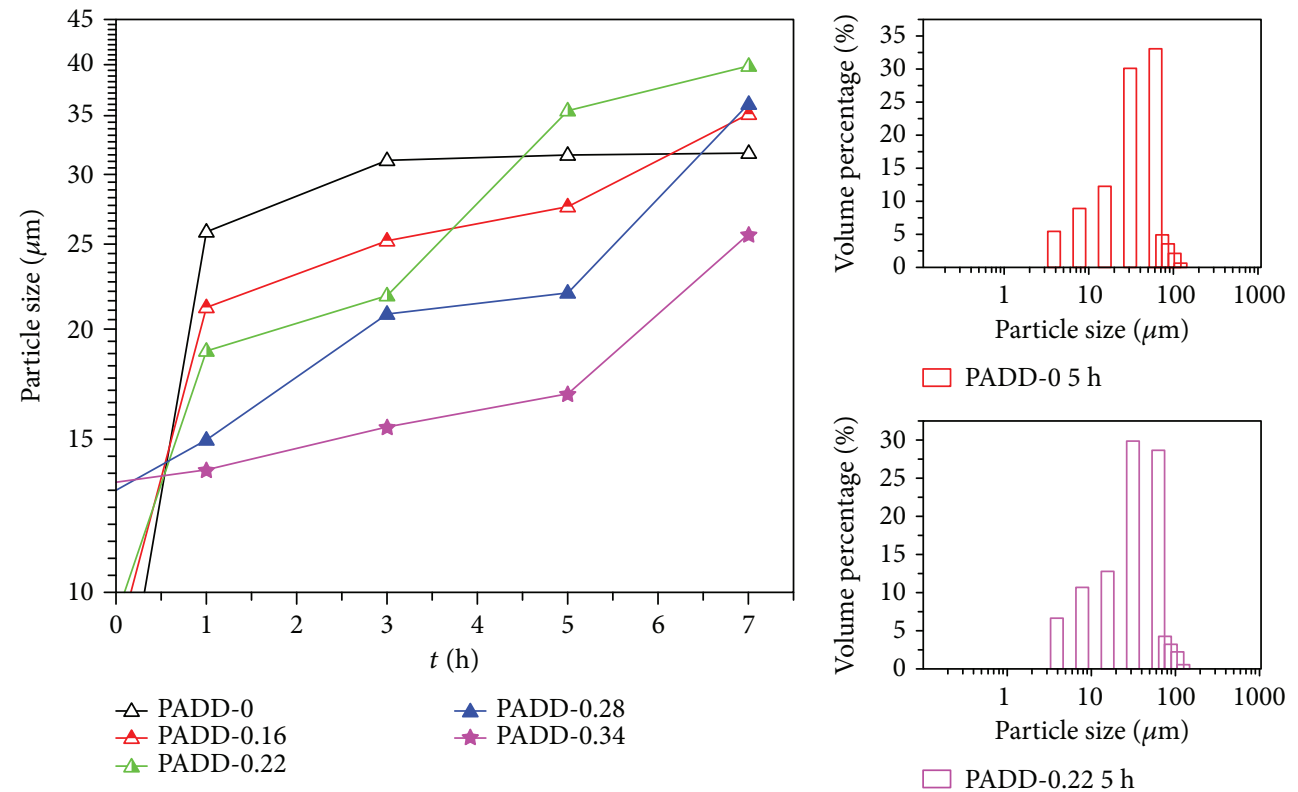

Figure 9: Relationship between particle size and swelling time for MAAE in $10176.6 \mathrm{mg} / \mathrm{L}$ brine at $25.0 \pm 0.1^{\circ} \mathrm{C}$.

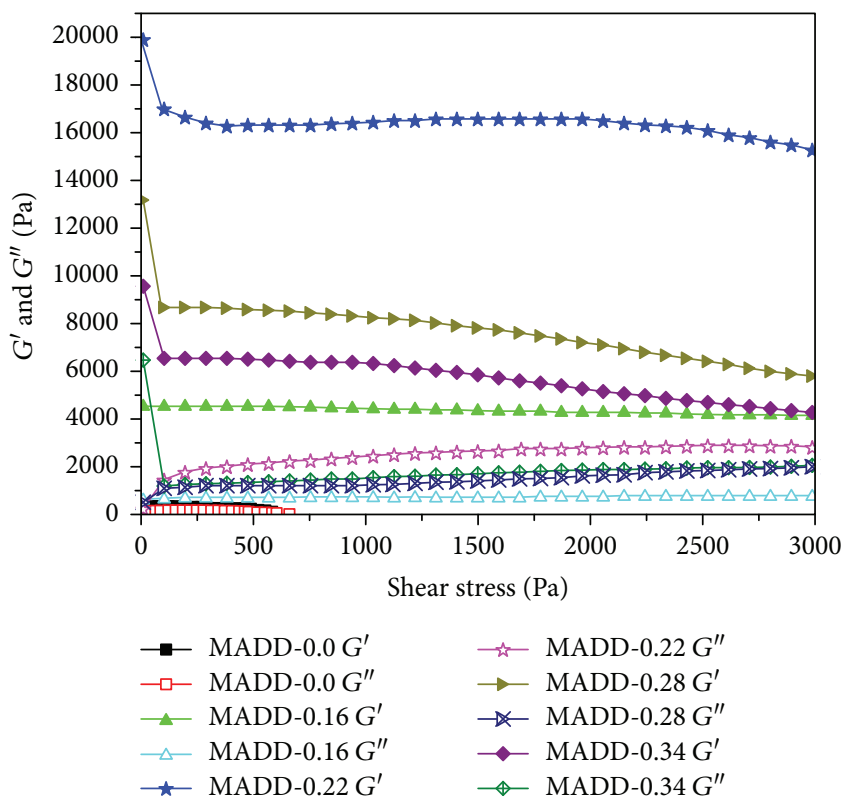

FIGURE 10: Curves of storage modulus, loss modulus, and shear stress at $45.0 \pm 0.1^{\circ} \mathrm{C}$.

experiments are showed in Figure 12 and Table 5. Clearly, the plugging properties of MADD increase first and then decrease with the rise of DEA concentration in the core with the permeability of $1500 \times 10^{-3} \mu \mathrm{m}^{2}$. MADD- 0.22 has the highest postgel water pressure in the five kinds of microspheres. In Table 5, in contrast to MADD-0.0, MADD-0.22 has the higher injection agent pressure gradient, the postgel water pressure gradient, resistance factor, and the residual resistance factor in the core with the permeability of $240 \times 10^{-3} \mu \mathrm{m}^{2}$.

The high plugging efficiency of MADD- 0.22 could be attributed to the swelling performance and viscoelasticity of

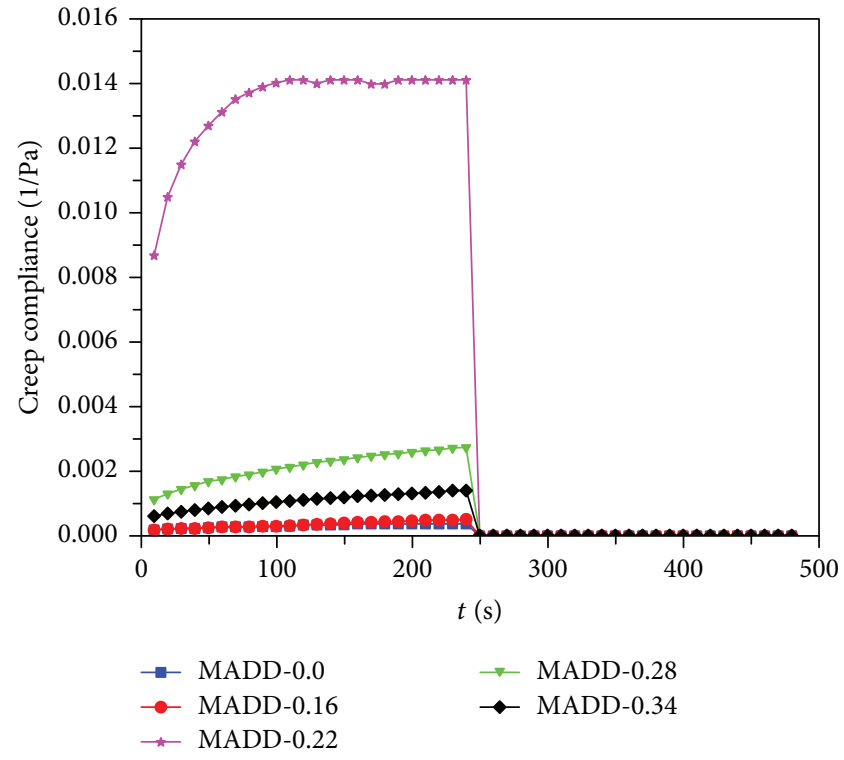

Figure 11: Curves of creep recovery at $45.0 \pm 0.1^{\circ} \mathrm{C}$.

microspheres. MADD microspheres are one type of water absorbent resin and induce good bridge after the water swelling in the formation. The bridging effect of microspheres would force water to flow around and increase the sweep efficiency through the formation of physical blocks in the core [47]. The slow swelling speed contributes to deep migration of MADD microspheres in the pores, which avoid accumulation at the wellhead. The microspheres with large swelling ratio can produce great additional pressure and strengthen their profile control ability in reservoir formation. However, MADD-0.22 has the slower swelling speed and the largest particle size of equilibrium swelling, which is in favor of injecting into the deep reservoir and effective plugging. Moreover, the viscoelasticity of microspheres 

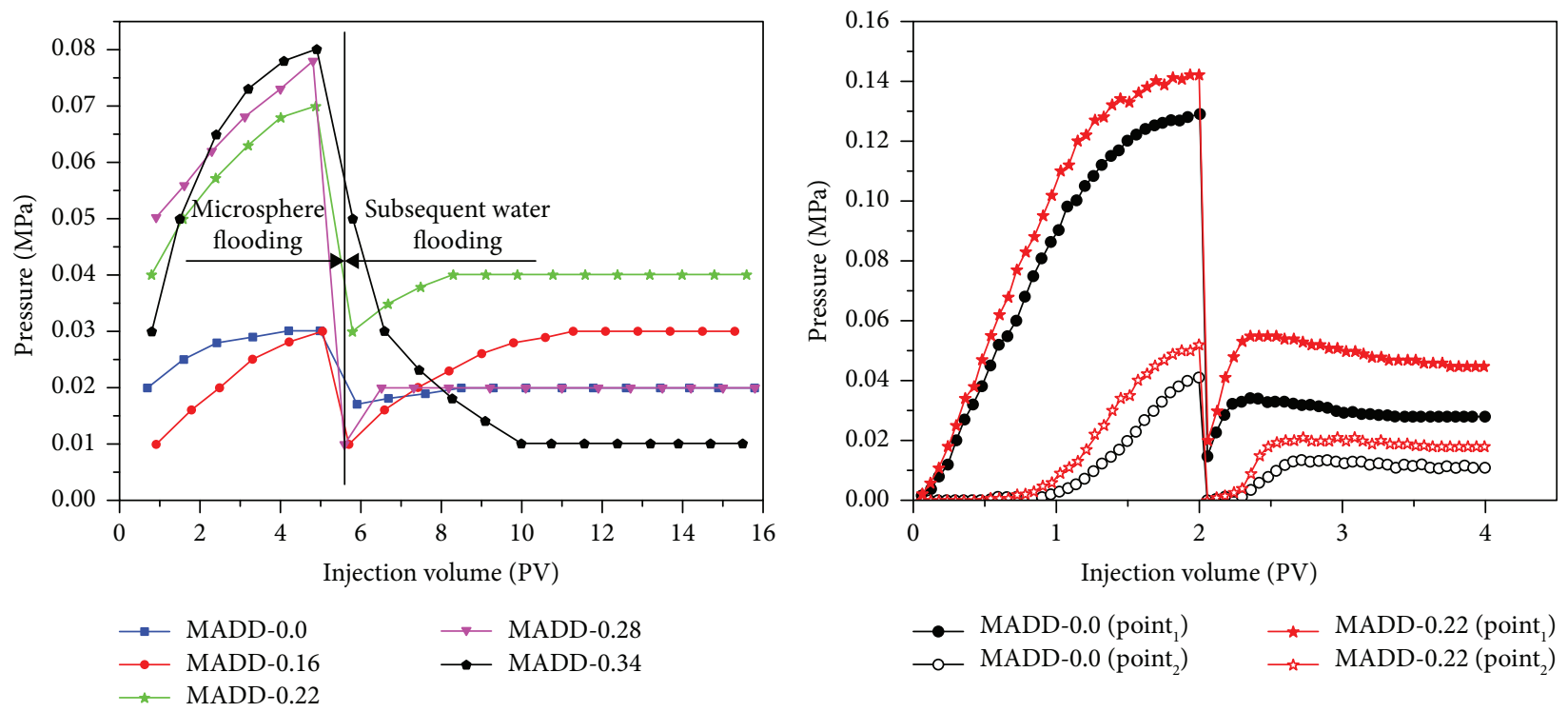

FIGURE 12: Variation of the injection pressures during the injection of the $3000 \mathrm{mg} / \mathrm{L}$ microsphere solution at $45.0 \pm 0.1^{\circ} \mathrm{C}$.

TABle 5: Blocking efficiency of microspheres in the cores.

\begin{tabular}{lcccccccccccc}
\hline \multirow{2}{*}{ Sample } & \multirow{2}{*}{$K_{\mathrm{i}} 10^{-3} \mu \mathrm{m}^{2}$} & \multicolumn{2}{c}{$(\Delta P / \Delta L)_{\text {basewater }}$} & \multicolumn{2}{c}{$(\Delta P / \Delta L)_{\text {microsphere }}$} & \multicolumn{2}{c}{$(\Delta P / \Delta L)_{\text {postwater }}$} & \multicolumn{2}{c}{ RF } & \multicolumn{2}{c}{ RFF } \\
& & Point $_{1}$ & Point $_{2}$ & Point $_{1}$ & Point $_{2}$ & Point $_{1}$ & Point $_{2}$ & Point $_{1}$ & Point $_{2}$ & Point $_{1}$ & Point $_{2}$ \\
\hline MADD-0.0 & 241.5 & 0.01 & 0.0067 & 0.43 & 0.27 & 0.093 & 0.073 & 43.0 & 29.3 & 9.3 & 7.9 \\
MADD-0.22 & 246.9 & 0.01 & 0.0067 & 0.47 & 0.35 & 0.15 & 0.12 & 47.3 & 37.1 & 15.0 & 12.9 \\
\hline
\end{tabular}

Note: the microspheres were dissolved by injection water, and test temperature was $45^{\circ} \mathrm{C}$.

greatly contributes to the migration depth and sweep volume in a larger degree. MADD-0.22 has the largest yield stress and creep conformance, which have contribution to the high shear resistance of microspheres to flushing and passing through the pore by elastic deformation under differential pressure. And the shear resistance increases the dimensional integrity of microspheres, contributing to the generation of the bridge effect in the in-depth pores after deformation recovery.

\section{Conclusions}

The hydrophobic association microspheres were prepared by the W/O emulsion method using the surface-active monomer DEA. The microspheres may be good materials for the rate-controlled swelling and swelling ratio. By varying the DEA content, we were able to easily monitor the swelling behavior of the microspheres. A higher DEA content prolonged the swelling rate during injection into the well bottom and reached the swelling equilibrium during migration into the deep reservoir, due to the contraction of the three-dimensional network of hydrophobic association and hydrogen bonding. Moreover, rheological performance was improved due to the increase of physical crosslinking of hydrophobic association chains and chain length between network junctions. The slower swelling rate and improved rheological performance greatly contributed to the plugging properties of microspheres in the pore. Thus, the DEA- modified hydrophobic association microspheres are useful in deep profile control.

\section{Conflicts of Interest}

The authors declare that there is no conflict of interest regarding the publication of this paper.

\section{Acknowledgments}

This work is supported by the National Basic Research Program of China (ZD201312), funded by the Key Projects of Natural Science Foundation of Heilongjiang Province, China.

\section{References}

[1] H. Q. Jiang, W. Zheng, X. S. Zhang, H. C. Bai, and M. F. Chen, "Dynamic law and method of judging effective time of early polymer flooding in Bohai Oilfield," Journal of China University of Petroleum, vol. 35, no. 6, pp. 94-95, 2011.

[2] J. Liu, X. Lu, and S. Sui, "Synthesis, evaluation, and gelation mechanism of organic chromium," Journal of Applied Polymer Science, vol. 124, no. 5, pp. 3669-3677, 2012.

[3] P. Zhang, Y. Dong, W. Huang et al., "Preparation, swelling properties, and displacement performance of functional amphiphilic microspheres," Journal of Applied Polymer Science, vol. 132, no. 10, 2015.

[4] M. Q. Lin, J. R. Guo, F. Q. Xu, G. Q. Zhang, M. Y. Li, and B. Peng, "Study on the matching between cross-linked 
polymer microspheres and nuclear-pore membranes," Advanced Materials Research, vol. 160-162, pp. 1346-1353, 2010.

[5] Z. Hua, M. Lin, J. Guo, F. Xu, Z. Li, and M. Li, "Study on plugging performance of cross-linked polymer microspheres with reservoir pores," Journal of Petroleum Science and Engineering, vol. 105, pp. 70-75, 2013.

[6] C. Yao, G. Lei, L. M. Cathles, and T. S. Steenhuis, "Pore-scale investigation of micron-size polyacrylamide elastic microspheres (MPEMs) transport and retention in saturated porous media," Environmental Science \& Technology, vol. 48, no. 9, pp. 5329-5335, 2014.

[7] Z. Hua, M. Lin, Z. Dong, M. Li, G. Zhang, and J. Yang, "Study of deep profile control and oil displacement technologies with nanoscale polymer microspheres," Journal of Colloid and Interface Science, vol. 424, pp. 67-74, 2014.

[8] C. Yao, G. Lei, L. Li, and X. Gao, "Preparation and characterization of polyacrylamide nanomicrospheres and its profile control and flooding performance," Journal of Applied Polymer Science, vol. 127, no. 5, pp. 3910-3915, 2013.

[9] C. Yao, G. Lei, X. Gao, and L. Li, "Controllable preparation, rheology, and plugging property of micron-grade polyacrylamide microspheres as a novel profile control and flooding agent," Journal of Applied Polymer Science, vol. 130, no. 2, pp. 1124-1130, 2013.

[10] Y. Q. Sun, Study on Mechanism of Enhanced Oil Recovery and Start the Residual Oil by Micro-Nano of Elastic Microsphere, [M.S. thesis], China University of Petroleum, Beijing, China, 2011.

[11] D. F. Song, Studies and Applications on the Deep Profile Control Technology of Functional Polymer Microspheres, [M.S. thesis], University of Shangdong, Qingdao, China, 2014.

[12] C. J. Yao and G. L. Lei, "Preparation and characterization of micron-sized elastic microspheres as a novel profile control and flooding agent," Advanced Materials Research, vol. 875877, pp. 257-261, 2014.

[13] J. Y. Hu, Synthesis and Performance of Polymeric Nanospheres Flooding Agent with High Strength and High Temperature Resistance, [M.S. thesis], Chengdu University of Technology, Chengdu, China, 2014.

[14] C. Katsuno, A. Konda, K. Urayama, T. Takigawa, M. Kidowaki, and K. Ito, "Pressure-responsive polymer membranes of slidering gels with movable cross-links," Advanced Materials, vol. 25, no. 33, pp. 4636-4640, 2013.

[15] Y. Xiang, Z. Peng, and D. Chen, "A new polymer/clay nanocomposite hydrogel with improved response rate and tensile mechanical properties," European Polymer Journal, vol. 42, no. 9, pp. 2125-2132, 2006.

[16] Z. Li, W. Mi, H. Wang, Y. Su, and C. He, "Nano-hydroxyapatite/polyacrylamide composite hydrogels with high mechanical strengths and cell adhesion properties," Colloids and Surfaces B: Biointerfaces, vol. 123, pp. 959-964, 2014.

[17] F. Delbecq, H. Endo, F. Kono, A. Kikuchi, and T. Kawai, "Incorporation of graphene into photopolymerizable hydrogels of $\mathrm{N}$-acyl glutanamides: rheological and swelling behavior study of soft nanocomposite materials," Polymer, vol. 54, no. 3, pp. 1064-1071, 2013.

[18] F. Sun, M. Lin, Z. Dong et al., "Nanosilica-induced high mechanical strength of nanocomposite hydrogel for killing fluids," Journal of Colloid and Interface Science, vol. 458, pp. 45-52, 2015.
[19] X. J. Liu, X. Y. Ren, S. Guan, H. Q. Li, Z. K. Song, and G. H. Gao, "Highly stretchable and tough double network hydrogels via molecular stent," European Polymer Journal, vol. 73, pp. 149-161, 2015.

[20] X. Qin, F. Zhao, and S. Feng, "Chemical modification and synthesizing conditions of nanocomposite hydrogels with high mechanical strength crosslinked by hydrophilic reactive microgels," Journal of Applied Polymer Science, vol. 122, no. 4, pp. 2594-2603, 2011.

[21] Y. Tan, P. Wang, K. Xu et al., "Designing starch-based nanospheres to make hydrogels with high mechanical strength," Macromolecular Materials and Engineering, vol. 294, pp. 855859, 2009.

[22] J. Yang, F. K. Shi, C. Gong, and X. M. Xie, "Dual cross-linked networks hydrogels with unique swelling behavior and high mechanical strength: based on silica nanoparticle and hydrophobic association," Journal of Colloid and Interface Science, vol. 381, no. 1, pp. 107-115, 2012.

[23] K. Xu, H. An, C. Lu, Y. Tan, P. Li, and P. Wang, "Facile fabrication method of hydrophobic-associating cross-linking hydrogel with outstanding mechanical performance and self-healing property in the absence of surfactants," Polymer, vol. 54, no. 21, pp. 5665-5672, 2013.

[24] J. Henise, B. R. Hearn, G. W. Ashley, and D. V. Santi, "Biodegradable tetra-PEG hydrogels as carriers for a releasable drug delivery system," Bioconjugate Chemistry, vol. 26, no. 2, pp. 270-278, 2015.

[25] X. Chen and K. Tsujii, "A novel hydrogel showing superrapid shrinking but slow swelling behavior," Macromolecules, vol. 39 , no. 25 , pp. 8550-8552, 2006.

[26] G. Jiang, C. Liu, X. Liu et al., "Network structure and compositional effects on tensile mechanical properties of hydrophobic association hydrogels with high mechanical strength," Polymer, vol. 51, no. 6, pp. 1507-1515, 2010.

[27] J. X. Liu, X. G. Lu, and J. F. Liu, "Mechanism and gelling effects of linked polymer solution in the core," Petroleum Exploration and Development, vol. 40, no. 4, pp. 507-513, 2013.

[28] Y. Guo, Y. Liang, X. Yang et al., "Hydrophobic microblock length effect on the interaction strength and binding capacity between a partially hydrolyzed microblock hydrophobically associating polyacrylamide terpolymer and surfactant," Journal of Applied Polymer Science, vol. 131, no. 16, 2014.

[29] B. Grassl, J. Francois, and L. Billon, "Associating behaviour of polyacrylamide modified with a new hydrophobic zwitterionic monomer," Polymer International, vol. 50, no. 10, pp. 1162 1169, 2001.

[30] Z. Zhu, W. Kang, B. Sarsenbekuly et al., "Preparation and solution performance for the amphiphilic polymers with different hydrophobic groups," Journal of Applied Polymer Science, vol. 134, no. 20, 2017.

[31] F. Jiang, W. Pu, Y. Li, and D. Du, “A double-tailed acrylamide hydrophobically associating polymer: synthesis, characterization, and solution properties," Journal of Applied Polymer Science, vol. 132, no. 38, 2015.

[32] S. Zhang, G. Huang, and J. Wu, "Rheological properties of template polymerization polyacrylamide aqueous solutions," Journal of Macromolecular Science, Part B, vol. 50, no. 11, pp. 2203-2213, 2011.

[33] L. Zhang, N. R. Brostowitz, K. A. Cavicchi, and R. A. Weiss, "Perspective: ionomer research and applications," Macromolecular Reaction Engineering, vol. 8, no. 2, pp. 81-99, 2014. 
[34] H. J. Lim, E. C. Cho, J. Kim, and I.-S. Chang, "Role of alkyl chain length and mole concentration of hydrophobic moiety in association behavior of amphiphilic polyelectrolytes in aqueous media," Colloids and Surfaces A: Physicochemical and Engineering Aspects, vol. 294, no. 1-3, pp. 71-79, 2007.

[35] C. Chang, M. He, J. Zhou, and L. Zhang, "Swelling behaviors of $\mathrm{pH}$ - and salt-responsive cellulose-based hydrogels," Macromolecules, vol. 44, no. 6, pp. 1642-1648, 2011.

[36] Y. Chen, D. Gao, Y. Tian, P. Ai, H. Zhang, and A. Yu, "Resonance light scattering technique for the determination of proteins with polymethacrylic acid (PMAA)," Spectrochimica Acta Part A: Molecular and Biomolecular Spectroscopy, vol. 67, no. 3-4, pp. 1126-1130, 2007.

[37] K. Naitoh, Y. Ishii, and K. Tsujii, "Iridescent phenomena and polymerization behaviors of amphiphilic monomers in lamellar liquid crystalline phase," The Journal of Physical Chemistry, vol. 95, no. 20, pp. 7915-7918, 1991.

[38] A. M. Lowman and N. A. Peppas, "Analysis of the complexation/decomplexation phenomena in graft copolymer networks," Macromolecules, vol. 30, no. 17, pp. 4959-4965, 1997.

[39] D. Serrano-Ruiz, P. Alonso-Cristobal, M. Laurenti, B. Frick, E. López-Cabarcos, and J. Rubio-Retama, "Influence of the inter-chain hydrogen bonds on the thermoresponsive swelling behavior of UCST-like microgels," Polymer, vol. 54, no. 18, pp. 4963-4971, 2013.

[40] C. Li, L. Xu, M. Zhai et al., "Swelling behavior of amphiphilic gels based on hydrophobically modified dimethylaminoethyl methacrylate," Polymer, vol. 50, no. 20, pp. 4888-4894, 2009.

[41] Q. Yu, X. Lu, J. Wang, Q. Guo, and L. Niu, "Effects of the charge ions strength on the swelling of organic-inorganic nanogels," Bulletin of the Korean Chemical Society, vol. 37, no. 7, pp. 1124-1131, 2016.

[42] Q. Yu, X. G. Lu, J. X. Liu, and K. Xie, "Rheological properties of poly(ethylene glycol)/poly(acrylamide-co-cellulose) semiinterpenetrating networks gel," Journal of Dispersion Science and Technology, vol. 36, no. 6, pp. 838-844, 2015.

[43] T. Narita, K. Mayumi, G. Ducouret, and P. Hébraud, "Viscoelastic properties of poly(vinyl alcohol) hydrogels having permanent and transient cross-links studied by microrheology, classical rheometry, and dynamic light scattering," Macromolecules, vol. 46, no. 10, pp. 4174-4183, 2013.

[44] E. Karpushkin and A. Bogomolov, "Morphology assessment of poly(2-hydroxyethyl methacrylate) hydrogels using multivariate analysis of viscoelastic and swelling properties," Polymer, vol. 58, pp. 222-229, 2015.

[45] E. Fernández, D. López, E. López-Cabarcos, and C. Mijangos, "Viscoelastic and swelling properties of glucose oxidase loaded polyacrylamide hydrogels and the evaluation of their properties as glucose sensors," Polymer, vol. 46, no. 7, pp. 22112217, 2005.

[46] Q. Y. Wu and J. G. Wu, Polymer Rheology, Higher Education Press, Beijing, China, 2012.

[47] K. Wang, J. C. Fang, and X. M. Wu, "Performance evaluation of polymer microspheres for profile control and oil displacement," Applied Mechanics and Materials, vol. 541-542, pp. 195-198, 2014. 


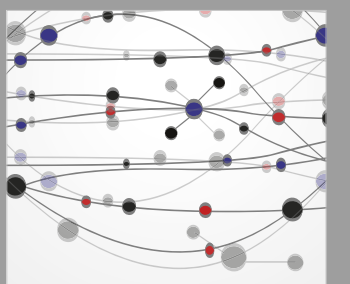

The Scientific World Journal
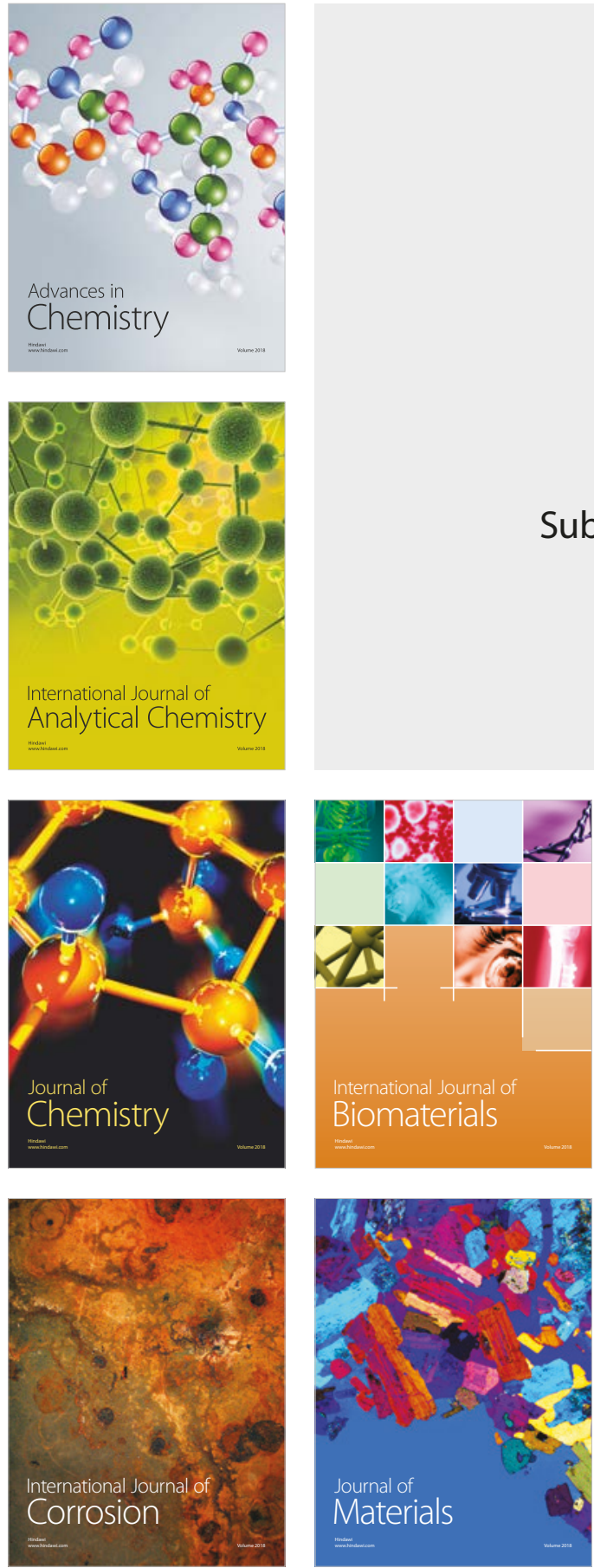

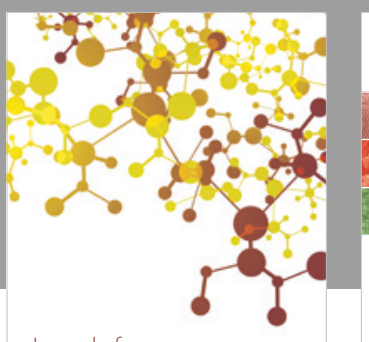

Journal of

Applied Chemistry
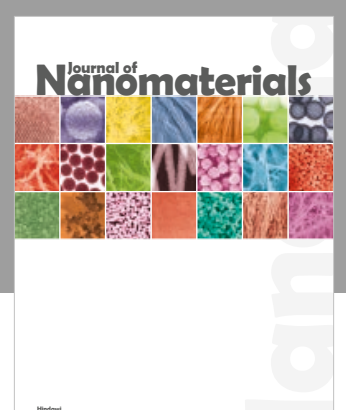

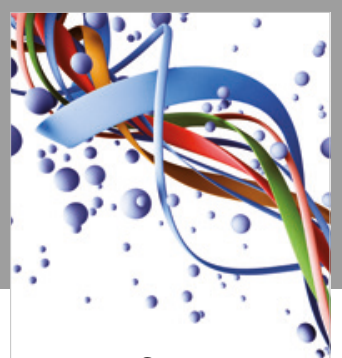

Scientifica

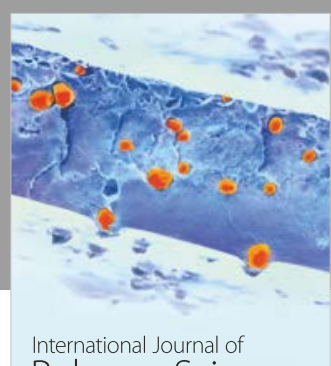

Polymer Science

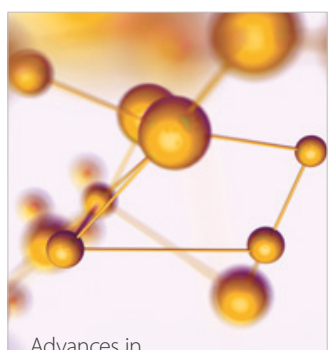

Physical Chemistry
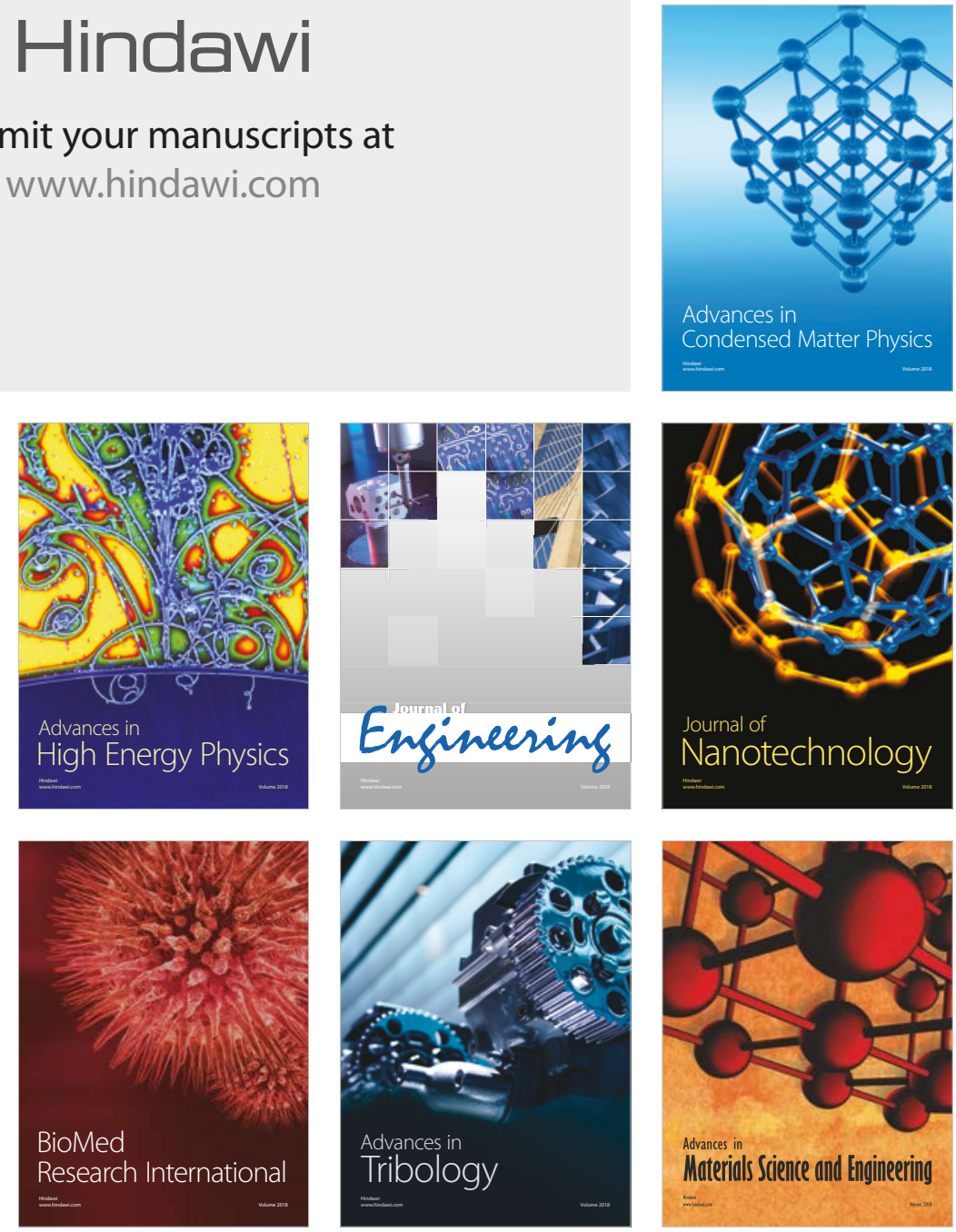